\title{
Theory development methodology process: Transformational leadership model for academic nurse leaders in South Africa
}

\author{
Sipho Wellington Mkhize* \\ School of Nursing and Public Health, College of Health Sciences, University of KwaZulu Natal, South Africa
}

Received: August 27, 2019

Accepted: December 15, 2019 Online Published: October 22, 2020

DOI: $10.5430 /$ jnep.v11n2p37

URL: https://doi.org/10.5430/jnep.v11n2p37

\begin{abstract}
Objective: The purpose of the article was to develop a transformational leadership model for academic nurse leaders in the nursing education institutions through theory development methodology process. This study emanated from objectives that were set into two phases whereby phase one formulated to enable the identification and classification of concepts in relation to transformational leadership of academic nurse leaders and phase two to develop and describe a model for transformational leadership for nursing education leaders in the Nursing Education Institutions.

Methods: An overarching theory generative design was adopted, in qualitative, quantitative, exploratory, descriptive and contextual nature. The theory generative design provided an understanding of the phenomenon of transformational leadership model development for academic nurse leaders in nursing education institutions. The research methods followed the strategy of theory development using concept, identification and classification, data collection methods and procedures, data analysis methods and processes to ensure the trustworthiness of the study, concept description and critical reflection of the model. The study was conducted at nursing education institutions from four Provinces of South Africa, namely, Gauteng, KwaZulu Natal, Free State, and Northwest.

Results: A visual structure was constructed after main and associated concepts were identified to give the researcher a diagram that relates to the process and structure for the incorporation of academic nurse leaders. The structure of the model was developed and gave an account of the content conceptually classified. There were four structural forms, which to convey hierarchical relations, differentiation, overlapping areas, and polarity and continuity. The structured model formed the conceptual relationships within the model and thereafter, emerged from relationships within the model, which included central elements of the model and consists of concepts, statements and relationships between concepts. The concepts addressed were agent (transformational leadership), recipient (followers), context (nursing education institution), procedure (transformational leadership), terminus/goal (empowerment) and dynamic (collaboration and partnership).

Conclusions: This article described the research design and method employed to develop a model for transformational leadership for nursing education leaders. A theory development, descriptive, exploratory, contextual, qualitative and quantitative research design in nature was described. The research objectives were formulated in two phases to enable exploration, identification, and definition of concepts (phase 1) and for model development (phase 2). Data collected though individual interviews for college principals and focus group interviews for vice-principals and subject heads and questionnaires for lecturers, students and administrative staff. Information regarding the sample size and number of participants the data collection method was discussed. The instrument used in this research including its reliability and validity, discussed in detail. Finally, the data analysis of qualitative and quantitative research methodology was highlighted.
\end{abstract}

Key Words: Analysis, Concept, Statement, Synthesis, Theory development, Theory, Transformational leadership

\footnotetext{
* Correspondence: Sipho Wellington Mkhize; Email: mkhizes4@ukzn.ac.za; Address: School of Nursing and Public Health, College of Health Sciences, University of KwaZulu Natal, South Africa.
}

Published by Sciedu Press 


\section{INTRODUCTION}

Transformational leadership is described and categorized as the most effective leadership model in the field of education and training management. ${ }^{[1-4]}$ Transformational leadership espouses a charismatic and inspiring role that drives employees to perform their duties beyond specified expectations in the formal job descriptions. ${ }^{[5]}$ Scientific studies attested that transformational leadership has five important dimensions namely, idealized attributes, idealized behaviours, inspirational motivation, intellectual stimulation, and individualized consideration. ${ }^{[6-8]}$ Contemporary studies concluded that successful school leadership is influenced by the relationship between leadership models and educational results. These successes have a positive impact on specific educational results including leaders' effectiveness, teachers' overall job satisfaction, and students' studying progress. ${ }^{[9,10]}$

Burns ${ }^{[11]}$ described transformational leadership as a process, not as a set of specific behaviours. According to Burns's arguments, transformational leaders are considered to have higher ideals, high ethical standards, and empowering features to make deep and basic changes. Burns ${ }^{[11]}$ argued that transformational leadership is more than an ordinary relationship between the leader and followers which occurs in transactional leadership. ${ }^{[12]}$ Transformational leadership provides deeper levels of relationship and high levels of commitment, performance, and ethical principles between the leaders and followers. ${ }^{[1]}$ The researcher identified that the research design and methodology that addressed theory development of model development for transformational leadership proved to be very scarce. The theory is critical to the research process in the provision of guidance and perspectives to the research study. According to Meleis ${ }^{[13]}$ theory is an organized, coherent, and systematic articulation of a set of statements related to significant questions in a discipline that are communicated in a meaningful whole. Thus, Dickoff et al. ${ }^{[14]}$ asserts that a theory is a coherent set of propositions and statements that describe (factor-isolating), explain (factor-relating), and predict (situation-relating) phenomena as well as prescribe (situationproducing) actions toward goals. The objective of the theory is to formulate a minimum set of generalizations that allow discipline to explain the maximum number of observable relationships among variables. This view is congruent with Dickoff et al. ${ }^{[14]}$ and Morris ${ }^{[15]}$ who observed that the purpose of theory is to describe, explain, and predict phenomena of discipline, and to guide and direct its practice. Nursing theories are very important for guiding education, research, practice and viewed as contributing to a well-founded basis for nursing practice. ${ }^{[16]}$ Chinn and Jacobs ${ }^{[17]}$ and Meleis ${ }^{[13]}$ confirmed that it is useful in describing nursing phenomena, in analyzing and explaining relationships among these phenomena, in predicting consequences, and in prescribing actions. The researcher proposed an intervention to address the gap in theory development process for transformational leadership of academic nurse leaders.

\subsection{Research questions}

- How to identify, classify concepts and their relatedness in the transformational leadership for academic nurse leaders? - How to develop and describe concepts for transformational leadership?

- How relational statements are constructed between concepts for the development of a model for transformational leadership for academic nurse leaders?

\subsection{Research aim}

The aim is to develop a model for transformational leadership for academic nurse leaders in nursing education institutions (NEI's').

\subsection{Objectives}

- To identify and classify the concepts for the transformational leadership model

- To develop and describe the concepts for the transformational leadership model

- To construct relational statements between concepts for the transformational leadership model

\section{METHODS}

\subsection{Research design}

An overarching theory generative design, which was qualitative, quantitative, exploratory, descriptive and contextual adopted. The theory generative design provided an understanding of the phenomenon of transformational leadership model development for academic nurse leaders. The research design allowed the researcher to become more involved with participants and concentrated on the particular meaning and significance of the situation of leaders in nursing academia. This was possible to explore the phenomena in an open, nonjudgmental manner, which is a preferred approach to when theory development research is undertaken as recommended by Chinn and Kramer. ${ }^{[16]}$ Each element is discussed below.

\subsection{Theory development}

Developing theory is the aim of all science and research. The theory is a set of interrelated constructs, definitions, and propositions that present a systematic view of phenomena by specifying relations among variables, with the purpose of explaining the phenomena and is based more on observation, design and data collection than on deduction. ${ }^{[18-20]}$ Theory development is a theory that is discovered, developed and provisionally verified through systematic data collection and 
analysis of data pertaining to that phenomenon. The theory development approach is the accumulation of scientific knowledge in a specific and orderly manner with a specific purpose or goal in mind as to remain focused. Firstly, it is the building of a theory that is faithful to and illuminates the area under study. ${ }^{[19,21]}$ In this article, the purpose of theory development was to develop a transformational leadership model for academic nurse leaders in nursing education institutions. Secondly, the purpose of this model was the development of the discipline, in this case describing guidelines for the operationalization of the transformational leadership model in promoting good leadership practice. ${ }^{[14,19,21,22]}$ Chinn and Kramer $^{[21]}$ and Walker and Avant ${ }^{[22]}$ implied that, in the end, there is a product, which demonstrates a creative structuring of the idea that projects a view of a phenomenon. This research is about developing a model that symbolizes a representation of empirical experiences. Models and theories are therefore, the formal expressions of empirical knowledge. According to Chinn and Kramer, ${ }^{[16]}$ Chinn and Kramer ${ }^{[21]}$ described empiric knowledge being developed though unique creative processes, catalyzed through critical questions such as what is this? and does it work? Additionally, Chinn and Kramer, ${ }^{[16]}$ Chinn and Kramer ${ }^{[21]}$ stated that a model is a form of theory and its description just like theory development it must follow logical reasoning. Therefore, reasoning strategies adopted in developing the model here analysis, synthesis, inductive reasoning and deductive reasoning, and discussed later in this article.

\subsection{Levels of theory development}

Chinn \& Kramer, Dickoff et al. discussed the proposed levels of theory development. Dickoff, James ${ }^{[14]}$ stated that theory exists on four levels: the first level and most basic are factor-isolating theories where concepts identified, classified, defined and analyzed. On the second level, factor relating or situation depicting theories represent a higher level of complexity in those concepts placed in relation to one another, and relationships between concepts were delineated. Situation-relating theories, on the third level also referred to as being of a predictive and promoting or inhibiting nature. The relations among the dimensions or characteristics of situations or events are developed by correlational research. To move beyond explanation to the predictions of precise relationships, they are generated and tested by empirical research; theories at this level are called middle-range theories. Finally, on the fourth level, situation-producing theories represent the highest level of theory development and are called grand theories.

Morse et al. ${ }^{[23]}$ discussed qualitatively derived theories under four levels or types: descriptive theory which describes and confirms evidence and is primarily context-bound; interpretive theory which enlightens and informs and is limited to the phenomenon under study; disclosive theory which reveals and, by the use of models, makes complex processes obvious and is process bound; and explanatory theory which explains and predicts and is thus broad in its generalisability.

Avant and Walker ${ }^{[24]}$ describe four levels of theory development: meta-theory, focusing on methodological and philosophical perspectives; grand-theories which define broad perspectives on the goals and structure of a discipline, middlerange theories which contain limited number of concepts and are testable; and practice theories which focus on a desired goal and prescribe actions which are needed to achieve the goal.

This article focused on the practice theory of nursing education and concepts were identified, defined, classified and analyzed. Relations were established between the concepts and the structure and process of the situation were described. The focus of this research was the development of a transformational leadership model and guidelines to be used in the theory-practice of nursing education.

From the above description, the linkages among these levels of theory development as seen in Figure 1.

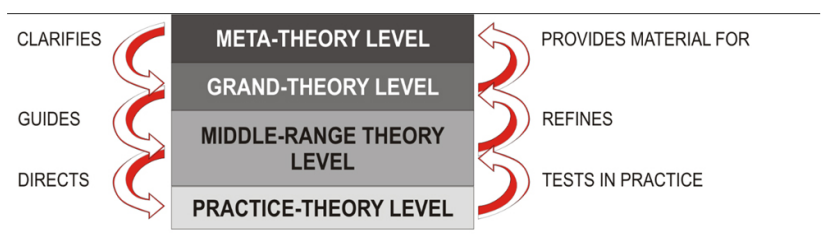

Figure 1. Interrelationships between levels of theory ${ }^{[22]}$

\subsection{Elements of development theory}

An understanding of the elements of theory and the basic approaches to building these elements is fundamental to the process of theory development. Walker and Avant ${ }^{[22]}$ proposed three elements of the theory, which when cross-tabulated with three overall approaches to theory development, provided a useful strategic guide to theory development. These elements included:

\subsubsection{Concepts}

Concepts are the most critical elements considered when undertaking theory generation based on the premise that they guide the process of investigation, which gives direction to theory generation. Concepts are generally referred to as a mental picture or an idea about a thing or an action which, are basic building blocks of theory. The function of concepts is for meaningful classification of people's experiences or views. The functionality of concepts was enhanced, when re- 
lationships stated between two or more concepts. Conceptual meaning created by describing the experiences of transformational leadership of academic nurse leaders, deputy academic leaders, subject heads, lecturers, students, and administrative staff. The results analysis was used to identify, classify and categorize important themes of factors concerning the experiences, which created conceptual meaning regarding transformational leadership. The researcher selected a concept in order to move closer to the goal of developing a model for transformational leadership for academic nurse leaders.

\subsubsection{Statements}

Statements formed the second element of theory used as either relational or non-relational. Relational statements according to Walker and Avant ${ }^{[22]}$ specify an association of some kind between two concepts. Non-relational statements, on the other hand, assert the existence of or define a concept. These statements served as adjuncts to each other and in so doing, helped to form meaningful connections needed to construct a theory. There were conclusion statements deduced from individual interviews, focused group interviews and multifactor leadership questionnaires (MLQ). Additionally, conclusion statements were deduced from the content analysis of the literature in the description of a conceptual framework. The basis for the relational statements of the model was formed from these conclusion statements.

\subsubsection{Theory}

Theory is a representation of a set of relational statements that are internally coherent and used to express new insights into a phenomenon of interest Walker and Avant. ${ }^{[22]}$ Concepts and statements are essential to theories and subsequently, theory development often begins with basic elements. Chinn and Kramer $^{[21]}$ asserted that the process of theory development required innovative and stringent structuring of concepts, which in turn imparted as relationship statements. Conceptual meaning was created as the basis of theory development to present a systematic view of phenomena explored. Academic nurse leaders were explored within the context of a nursing education institution and result, systematic model development (see Table 1).

Table 1. Cross-tabulation of elements of theory and approaches to theory development ${ }^{[22]}$

\begin{tabular}{lll}
\hline $\begin{array}{l}\text { Elements of } \\
\text { theory }\end{array}$ & Approaches to theory development & \\
\cline { 2 - 3 } & Analysis & Synthesis \\
\hline \multirow{3}{*}{ CONCEPT } & $\begin{array}{l}\text { Plan: a concept analysis } \\
\text { Application: clarify/refine existing concept }\end{array}$ & $\begin{array}{l}\text { Application: } \\
\text { pull together concepts from a set of data }\end{array}$ \\
\multirow{2}{*}{ STATEMENT } & $\begin{array}{l}\text { Plan: statement analysis } \\
\text { Application: clarify/refine a body of statements }\end{array}$ & $\begin{array}{l}\text { Plan: statement synthesis } \\
\text { Application: pull together statements from a set of data }\end{array}$ \\
\multirow{2}{*}{ THEORY } & Plan: theory analysis & $\begin{array}{l}\text { Plan: theory synthesis } \\
\text { Application: pull together a theory from a set of data or } \\
\end{array}$ \\
\hline
\end{tabular}

Due to different, yet convergent processes for theory development proposed, the researcher constructed a process to enable meaningful, contextual model development (see Table 2).

The detailed strategy of theory development was addressed in the appropriate sub-sections.

\subsubsection{Analysis}

The researcher used the strategy of data analysis of the empirical research for the purpose of identification of concepts and searching for relationships between statements to develop the model for transformational leadership for academic nurse leaders (ANLs). Analysis of literature was preceded by the identification and classification of the concepts. Walker and Avant ${ }^{[22]}$ affirmed that analysis engages in activities of dissecting, that is breaking down, and the reduction of a complex whole into component parts for the purpose of clarifying, refining and mostly better understanding, followed by sharpening of concepts, statement or theories and then examining the relationship of each of the parts to each other and to the whole.

\subsubsection{Synthesis}

The strategy of synthesis involved merging, joining and combining seemingly isolated pieces of information together in a new light. This was useful in theory development, helped to construct a new concept, a new statement or even a new theory as asserted by Walker and Avant. ${ }^{[22]}$ Synthesis alternates with analysis when used during data analysis to draw inferences and endorsements based on the discoveries from empiric research. The researcher explored and described concepts relevant to the model of transformational leadership for ANLs. 
Table 2. Combinations of stages of theory development ${ }^{[14,21]}$

\begin{tabular}{|c|c|c|}
\hline Chinn and Kramer (2014) & Dickoff, James and Weidenbach (1968) & Phases used in this research study \\
\hline $\begin{array}{l}\text { First Level: } \\
\text { Creating conceptual meaning } \\
\text { Identification description and definition } \\
\text { of concepts }\end{array}$ & $\begin{array}{l}\text { Factor isolating theory Naming theory: } \\
\text { Conceptual ideas-descriptive in nature }\end{array}$ & $\begin{array}{l}\text { Concept identification } \\
\text { Concepts description }\end{array}$ \\
\hline $\begin{array}{l}\text { Second level: } \\
\text { The meaning created is structured and } \\
\text { conceptualized } \\
\text { Multiple concepts are linked in a loose } \\
\text { structure }\end{array}$ & $\begin{array}{l}\text { Factor relating theory depicting the situation } \\
\text { Concepts are no longer in isolation } \\
\text { The higher level of complexity }\end{array}$ & Relating and structuring concepts \\
\hline $\begin{array}{l}\text { Third level: } \\
\text { Generation of theoretic relations and the } \\
\text { testing thereof: } \\
\text { Empirical and grounding } \\
\text { Emerging relationships } \\
\text { Empiric indicators } \\
\text { Validating relationships }\end{array}$ & $\begin{array}{l}\text { The situation relating to the theory } \\
\text { Prediction of theory with the aim of allowing the } \\
\text { prediction of relationships between situations } \\
\text { that are despicable. }\end{array}$ & $\begin{array}{l}\text { Prediction of relationships: } \\
\text { Description of structure and process } \\
\text { of theory model }\end{array}$ \\
\hline $\begin{array}{l}\text { Fourth level: } \\
\text { Deliberate application of theory in } \\
\text { clinical theory } \\
\text { The outcome variable is determined for } \\
\text { the practice method of study is } \\
\text { implemented }\end{array}$ & $\begin{array}{l}\text { Situation producing theory: } \\
\text { Prescriptive in nature } \\
\text { Goal content specified as the aim of the activity } \\
\text { Prescriptions for an activity to realize goal } \\
\text { content } \\
\text { Survey list as a supplement }\end{array}$ & $\begin{array}{l}\text { Description of guidelines for } \\
\text { operationalization of the model }\end{array}$ \\
\hline
\end{tabular}

\subsubsection{Inductive reasoning}

The researcher used an inductive approach to make predictions about novel situations based on existing knowledge or hypothesis as recommended by Yilmaz. ${ }^{[25]}$ The researcher used an inductive reasoning strategy to construct meaning from diverse experiences expressed during the focus groups and individual interviews through facilitated discourse to strengthen arguments that might alter conclusions until a saturation point was reached. The collected data was analyzed and interpreted through inductive abstraction and generalization. ${ }^{[21]}$ The empirical findings assisted to generate core concepts and relational statements for the model of transformational leadership.

\subsubsection{Deductive reasoning}

The use of a scientific conceptual framework resulting from the results of concept analysis to direct the collection and analysis of empirical data. Data analysis and arguments were undertaken during conceptualization to provide conclusive grounds of relational statements. Deductive reasoning was therefore useful in literature contextualization whereby conclusions were drawn from data analysis; development of the model once constructs were identified and described; and development of guidelines for the implementation of the model. In this research, deductive reasoning was therefore useful in the following instances; literature contextualization; in conclusions drawn from data analysis; in the development of the model once constructs have been identified and described and in the development of guidelines for the implementation of the model.

\subsubsection{Idle method $^{T M}$}

The description of deductive and inductive reasoning was used in the development and description of the model. However, the researcher moved beyond the reasoning and used the conclusion statements as "evidence" in the model development. This method is referred to as the IDLE Method ${ }^{\mathrm{TM}}$, which is referred to as "inductive and deductive logic evidence". ${ }^{[26,27]}$ It was a process where logical reasoning was used, inductive and/or deductive by generating conclusions from the empirical data and/or literature. The conclusions served as evidence for the relational statements. ${ }^{[26]}$ An assumption of this method was that it was possible to distinguish correct reasoning from incorrect reasoning based on the arguments presented. The structure of an argument was the fundamental unit of an argument that was rejected and this proposition (or statement) was typically expressed as a declarative sentence (or called a conclusion). ${ }^{[26]}$ The premise and the conclusion were defined in relation to each other within a given argument. ${ }^{[27]}$ An argument was differentiated from collective proportions, by the inferences between statements to draw a conclusion. The application of the IDLE Method $^{\mathrm{TM}}$ in the study was by generating conclusions from the empirical data and literature. The conclusions provided 
evidence for the formulation of the relational statements. The IDLE Method $^{\mathrm{TM}}$ ensured the rigor of the theory, as an audit trail of evidence of the reasoning process can be provided ${ }^{[26]}$ (see Figure 2).

\subsection{Qualitative}

The researcher employed the qualitative method to develop concepts, explore meaning, describe realities to produce a generalizable theory. In a qualitative approach, the researcher obtained an explanation of what experiences academic nurse leaders have in relation to transformational leadership through in-depth interviews and focus group interviews. The insight gained from the process guided the model description and guidelines to operationalize the model.

\subsection{Quantitative}

The researcher used the quantitative method to test the hypothesis and establish facts to predict outcomes. The quantitative research described leadership styles practiced by ANLs as observed by lecturers, administrative staff and students in the nursing education institutions, explored and discussed in MLQ. According to Burns, Grove, ${ }^{[20]}$ Polit and Beck, ${ }^{[28]}$ Babbie, ${ }^{[29]}$ there are different types of social research methods that can be identified from the literature, namely exploratory, descriptive and explanatory research.

\subsection{Explorative}

The researcher used an exploratory design to gain insight into and comprehending whether the phenomena had a deeper meaning. Extensive literature was explored during conceptualization. This design identified and discovered important variables to generate a hypothesis for further research. ${ }^{[28,30]}$ As this investigation focused on an inadequately understood phenomenon that had a deeper meaning to it, the researcher had to remain "open" to any new ideas as they emerge so that a meaningful explorative process could be facilitated as affirmed by Burns, Grove ${ }^{[20]}$ and Denzin and Lincoln. ${ }^{[31]}$

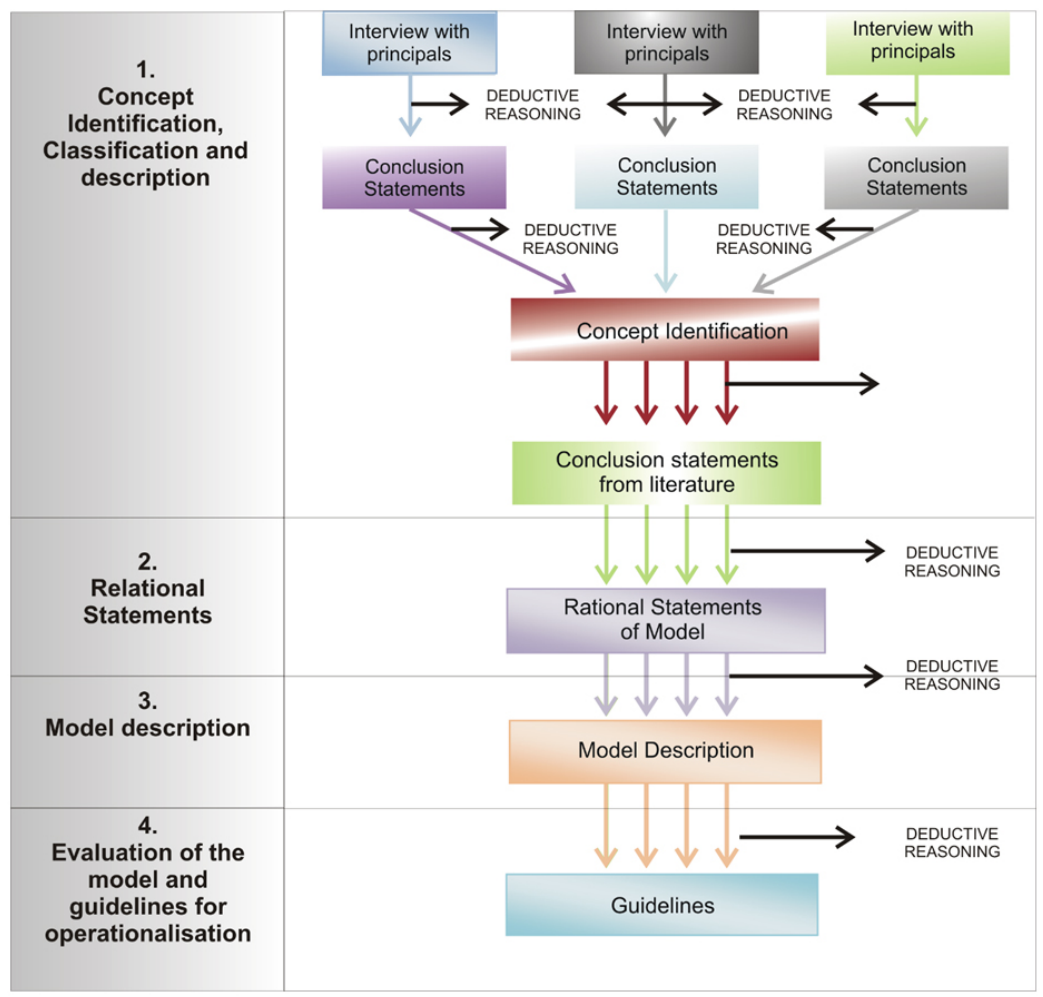

Figure 2. Schematic diagram of IDLE Method ${ }^{\mathrm{TM}}$ in theory development ${ }^{[26]}$

\subsection{Descriptive}

The researcher engaged in deductive reasoning to deduce from contextual data analysis to conceptualize research findings. An accurate description conceptualization formed the core of the research study as relational statements were analyzed and stated deductively. The description is interpretive, therefore data collected accurately, meaning that done by describing and documenting the situation as it naturally occurs. $^{[20]}$

\subsection{Contextual}

The intention of a contextual approach was not to generalize the findings beyond this context but to describe and comprehend experiences with the unique dynamic environ- 
ment of nursing education institutions during transformation. The context thus was unique because there was a dichotomy between two Ministries of Education and Health, in South Africa where NEIs' are managed and funded by Provincial Departments of Health, yet any institution of teaching and learning offering programmes pegged at National Qualifications Framework (NQF) level 5-10 fall under the auspices of National Department of Education. ${ }^{[32]}$

\subsection{Research method}

For the researcher to develop a model for transformational leadership it was imperative to understand what ANLs, lecturers, students and administrative staff are experiencing about leadership style. The research method followed the strategy of theory development steps of concept identification, classification, and description; construction of relational statements; structure and process description of the model and model evaluation and guidelines for operationalization of the model. These steps of theory development were described below in detail:

\subsubsection{Concept, identification, and classification}

According to Chinn et al. ${ }^{[16,21]}$ concept identification is the process of identifying concepts that form the basic fab- ric of theory. Concepts were identified through a critical literature review approaches for the incorporation process. Concept identification followed by concept classification and concept description utilized the "survey list" of Dickoff, et al. (1968:420), which corresponded with their first level of theory. Concept classification is sorting, categorizing, assigning names in terms of belonging to one kind as opposed to another. In concept classification, concepts were sorted, put together and related one to the other according to their relatedness. The function of their level one theory, factor isolation theory, and (practice-theory) required concepts to be classified and categorized. It reduced the abstractness of the concepts and consequently, they became clearer as attributes added to them. This improved the chances of making them become applicable. After classifying these concepts, definition, and description of concepts was concluded. This improved the chances of making them become applicable. Data collection from phases 1(a) (individual interviews; focus group interviews) and 1(b) (multifactor leadership questionnaires) utilized to meet objectives of phase 2 namely, formulation of relational statements and model development. The methodology of data collection for concept identification discussed in the next section. The identification and classification of concepts are presented in Figure 3.

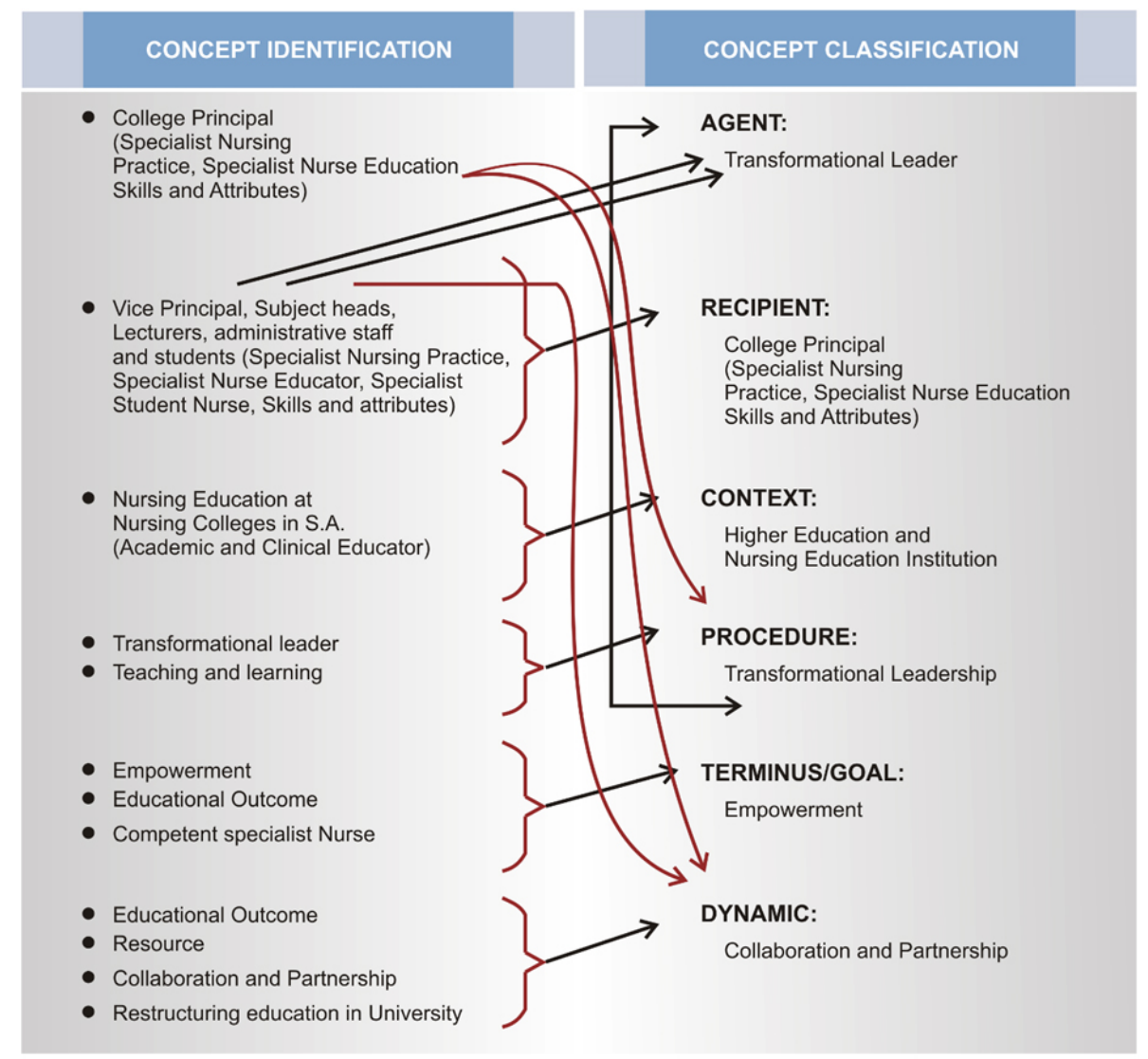

Figure 3. Identification and classification of concepts 


\subsubsection{Data collection}

\section{1) Individual interviews}

The study participants eight (8) were drawn from four Provinces of South Africa with an open invitation via electronic media was used. The researcher adopted a purposive sampling, to discover, understand and gain insight so that the researcher could learn the most as recommended by Polit, Gray, Seidman. ${ }^{[28,30,33]}$ The sampling criteria included the work experience of not less than five years as ANLs; registered nurse and nurse educator with the SANC; employed in the NEIs, and able to communicate in English. The size of the sample determined by the saturation of the data. The researcher conducted qualitative research interviews to discover illustrations of real-life experiences in order to interpret the meaning of the described phenomena. The researcher interpreted the meaning of core themes, encoding and interpreting the meaning of what is spoken and how it is reported. The in-depth individual interviews were conducted to allow participants to describe their viewpoints perspectives in relation to their experiences limitless. Data collected during field-work was used to supplement data already collected during in-depth interviews. The phenomenon was the experiences of transformational leadership in NEIs. Therefore, building theory from exploration and description of participants' experiences was very significant. The same openended question that was asked at the beginning, utilizing the interview with various communication techniques to gather more information until data was saturated.

\section{2) Focus group interviews}

The participants (deputy academic nurse leaders, subject heads: 35 ) selected as per criteria as outlined in the individual interviews section. The purposive sampling method was applied to discover, understand, gain insight and the researcher can learn the most. Focus group interview methodology employed to participants that have something in common and a driving force behind the key topic to be addressed. ${ }^{[34-36]}$ The researcher opted for an investigative, facilitator and moderator role in order to control dynamics, engaging dialogue that stimulated discussion rather than generating answers. The researcher took the periphery role rather than a central role. The research questions that guided the focus group interviews: "What are your experiences of transformational leadership in your nursing college?" Each session lasted more or less one hour and thirty minutes. The researcher applied the interactive facilitative techniques to encourage discussion, which continued until the saturation point of the information was reached.

\section{3) Multifactor leadership questionnaires (MLQ)}

The participants selected with an open invitation to complete MLQ within thirty to thirty-five minutes. A non-probability technique, convenient sample was used. This method involved collecting information from participants who were conveniently available at the time of the research. The main reason for choosing the convenience sampling method was that there was no reason to generalize the results to the entire population but to gain more insight into the subject of inquiry. It was the fastest approach considering the spread of Provinces selected for research. The sample of 120 lecturers, 42 administrative staff, and 348 students using EXCEL random generator on participants. The participants received questionnaires that were distributed through the internal mailing system. The specific instructions on completing, contact details provided in the event of any queries or problems that may have arisen during participation in filling in questionnaires and the importance of personally completing all questions were included. MLQ, the latest version, Form 5 X (Revised) was used in this research. The questionnaire consisted of forty-five (45) statements that identify and measure the key aspects of leadership behaviours. Each participant was required to assess and testify as to how frequently the behaviours described by each statement of the statements exhibited by their ANLs. The MLQ consisted of two versions known as "rater version" and the "self-rater version".

\section{4) Reliability and validity of the instrument}

The researcher conducted confirmatory factor analyses (CFAs) in order to test the factorial validity of the MLQ-5X. In accordance with Antonakis, Avolio, ${ }^{[37]}$ Avolio, Bass ${ }^{[38]}$ the researcher evaluated various antagonizing approaches that had been identified by these scholars. In order to evaluate the aspects of reliability evaluated and calculated by following three independent approaches (internal consistency (Cronbach's Alpha), the interrater agreement (IA) and the test-retest-reliability (RTT)). According to Cortina, ${ }^{[39]}$ internal consistency was calculated for each of the MLQ-5X subscales. The process of coding questionnaires was conducted by capturing scores onto a Microsoft EXCEL spreadsheet for statistical analysis. The scores then imported into Statistica (an adept analysis) for analysis (in SPSS, 2015). The schematic diagram summarised objectives through a flow chart represented in Figure 4.

\subsection{Data analysis}

\subsubsection{Qualitative analysis}

The researcher arranged data according to an appropriate part of the thematic framework to which they relate and form chunks. The process of mapping and interpretation was influenced by the research objective and themes that have emerged from data collection. The most descriptive word for the identified theme was sought and used to classify the information into categories and subcategories. The field notes 
were used to make inferences on themes pertaining to the categories and subcategories. The raw set of data was given to an independent analyst and was provided a protocol for data analysis. Henning et al.. ${ }^{[40]}$ Pope et al. ${ }^{[41]}$ concluded that when a researcher is satisfied that the themes represent a reasonable "research chunk" of reality, each theme can be used as the basis for an argument in a discussion around them.

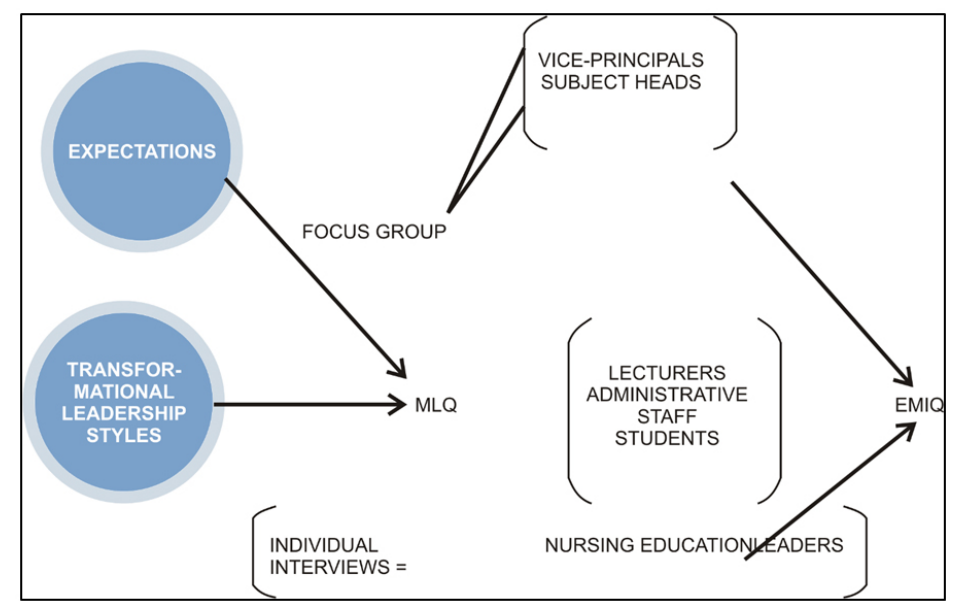

Figure 4. The flow diagram for depicting phase 1(a) and (b) objectives

\subsubsection{Quantitative analysis}

The statistical techniques were applied to analyze the information. Using the Statistica computer program, a two-tailed Pearson correlation analysis conducted to test the hypothesis of this research (using Statsoft, 2015). Data was subjected to data analysis in terms of biographical data, leadership empowerment, leadership abilities, leadership interpersonal relationship, and leadership communication process. The correlation analysis helped in both the form and the degree of the relationship between transformational leadership and leadership styles. Thus, both the strength of the relationship between variables and the level of statistical significance was assessed.

\subsection{Model development}

Since theories comprised of concepts, definitions, and statements and graphically represented as models, these need to be developed systematically for successful model development. The strategies for model development have been selected according to the writings of Walker and Avant ${ }^{[22]}$ (see Table 3).

Table 3. Approach to model development

\begin{tabular}{|l|l|}
\hline ELEMENTS OF THEORY & RESEARCHER'S APPROACH TO MODEL DEVELOPMENT \\
\hline \multirow{3}{*}{ Concept identification } & $\begin{array}{l}\text { Strategy: Concept synthesis } \\
\text { Use: To identify concepts based on empirical data } \\
\text { Rationale: Available concepts were limited and generally unexplored }\end{array}$ \\
\hline \multirow{5}{*}{ Statement development } & $\begin{array}{l}\text { Strategy: Statement synthesis } \\
\text { Use: To construct relationships by way of relational statements between two or more concepts } \\
\text { developed above } \\
\text { Rationale: Evidence available in data generated from individual and group interviews and from } \\
\text { Theory Development }\end{array}$ \\
& $\begin{array}{l}\text { Strategy: Theory synthesis } \\
\text { Use: To pull together relational statements in a coherent manner to represent the model for nursing } \\
\text { education leaders } \\
\text { Rationale: Availability of systematically developed relational statements }\end{array}$ \\
\hline
\end{tabular}

\subsection{Concept description}

Walker and Avant ${ }^{[22]}$ considered concept development is a crucial yet often neglected component of theory developPublished by Sciedu Press

Published by Sciedu Press ment. They posited three conditions, which necessitated concept development. Walker and Avant ${ }^{[22]}$ suggested that if any of the three conditions were lacking, then one of the 
concept development strategies was concept analysis, and concept synthesis or concept derivation were selected for concept development. The concept synthesis was developed from the results and literature contextualization of individual interviews and focus group interviews explained as a strategy. This strategy was implemented to generate new ideas and to examine the data of new insights that can enhance theory development. In describing the specific procedures for concept synthesis, Walker and Avant ${ }^{[22]}$ refer to three approaches, which include qualitative, quantitative and literary approaches. The literary approach required a careful review of the literature for acquiring new insight into the phenomenon. Walker and Avant ${ }^{[22]}$ proposed several steps in concept analysis, which are "reiterative" rather than sequential.

\subsection{Formulation and model description}

The researcher carefully selected a strategy for statement development based on the judgment of the state of the art of existing knowledge about the research topic. Walker and Avant $^{[22]}$ described statement synthesis as an empirically based strategy, which aims at specifying relationships between two or more concepts derived from evidence and has its purpose, the development of one or statements about relationships that exist between these concepts. Therefore, statement synthesis requires data as a point of departure and involves the logical processes of moving from observations to inferences (deductive logic) and then generalizing from specific inferences to more general, abstract ones (inductive logic). Quantitative and qualitative methods proposed for inferring from empirical observations and literary methods for moving from specific to general inferences. ${ }^{[22]}$

In describing, the structure of the model attention was given to the components integral to the building of the model. The structure of the model gave an account of the content conceptually classified according to the survey list of Dickoff et al. ${ }^{[14]}$ Chinn and Kramer ${ }^{[21]}$ proposed four structural forms, which assisted to convey particular ideas such as hierarchical relations, differentiation, overlapping areas, and polarity and continuity. These authors asserted that some models reflect a combination of these structural forms and those individual concepts within a model structured in these forms. The structure of the model gave overall form to the conceptual relationships within the model and emerged from relationships within the model. ${ }^{[21]}$ The structure included central elements of the model and consists of concepts, statements, and relationships between concepts. The concepts addressed were agent (transformational leadership), recipient (followers), context (nursing education institution), procedure (transformational leadership), terminus/goal (empowerment) and dynamic (collaboration and partnership). ${ }^{[14]}$

The triangular drawing suggested leadership is composed of a series of related sub-concepts that vary in breadth or simplicity. It also suggested foundational concepts on which other sub-concepts built. The overlapping circles depicted discrete components that have common areas between and among them. The horizontal line drawing showed empowerment represented as a continuum in a linear relationship with transformational leadership. The last drawing conveys the idea of differentiation dividing major concepts into subconcepts. The model was visually displayed by means of different structures such as triangles, overlapping circles, horizontal lines, and arrows. The structural form depicted in Figure 5.

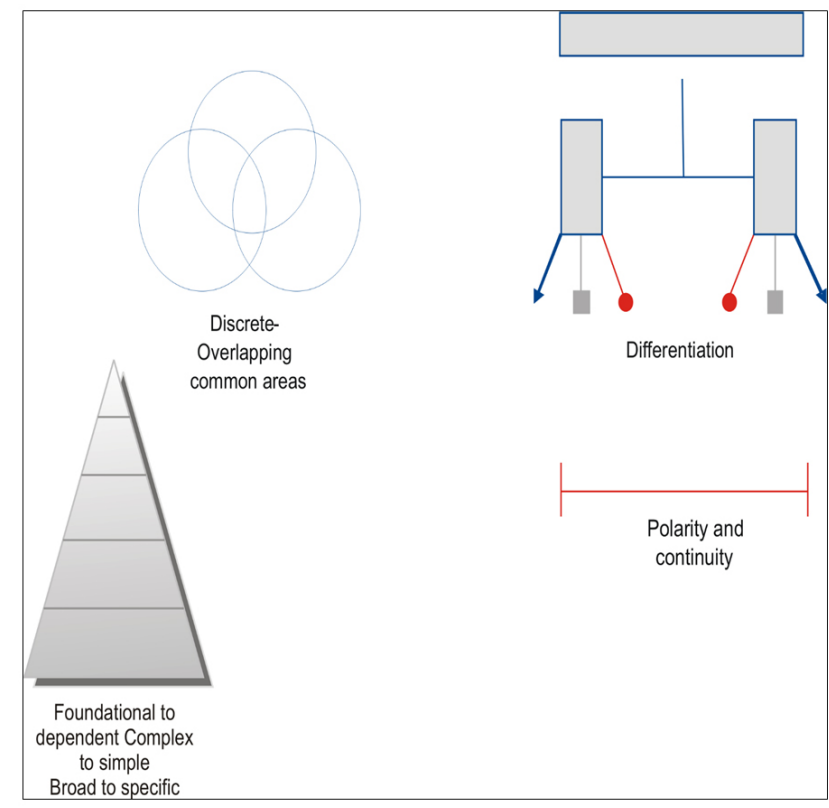

Figure 5. Managers' and nurses' competence assessments

\subsection{Critical reflection of the model}

Chinn and Kramer ${ }^{[21]}$ stated that analytic and evaluative processes that were useful in understanding the nature and value of the theory. These processes described and critically reflected theory, that is, examined its value for various purposes. A clear understanding of the nature of any theory flows from the description and critical reflection. Critical reflection contributed to understanding how the theory relates to practice, research or educational activities. The critical reflection of the model addressed through semantic clarity: The definitions of concepts in this theory were an important aspect semantic clarity because it helped to establish the empirical meaning for concepts in this theory. The concepts in this study were clearly defined. It reflected both general and specific traits, semantic consistency meaning that the con- 
cepts of this theory used in ways that were consistent with their definition. No other meanings for definitions within this theory were implied. There was a consistent use of basic assumptions within this theory, structural clarity referring to how understandable the connections and reasoning within the theory are. In this theory, concepts were interconnected, organized into a coherent whole., structural consistency: Structural consistency is related to the use of different structural forms within the theory. Consistency throughout the theory concerning structure was reflected in the relationships, simplicity of the model became evident through the minimum elements in each category. The researcher comes to the conclusion from the discussion that this model is not complex. The core concepts support the purpose of the model and are self-evident, the generality of a theory referred to its breadth of scope. The scope of concepts and purposes within this theory provided clues to its generality, accessibility refers to how attainable the projected outcomes of the theory are. Concepts can be made empirically accessible through generating and testing relationships, deliberative application of the theory and clarifying conceptual meaning and the importance of the model is closely tied to the idea of its clinical significance or practical value. The importance of the model has to do with the applicability and the practical value of the theory generated in it.

\subsection{Ethical considerations}

The researcher adhered to the principles of ethics (autonomy, justice, and beneficence) that guided the research study. The ethical clearance was obtained from the University and four Provincial Departments of Health. The roles and responsibilities of participants were clearly defined and their rights to the research study were guaranteed. The research data to be kept for (5) years and deleted thereafter, according to the University's policy on storage and management of research data.

\subsection{Trustworthiness}

Lincoln and $\mathrm{Guba}^{[42]}$ identified the four criteria (credibility, dependability, conformability, and transferability) for developing trustworthiness of qualitative inquiry, which are described fully:

\subsubsection{Credibility}

This criterion refers to the confidence in the truth of the data and interpretations thereof. Researchers need to ensure that the confidence in truth findings for each participant and the research is established. ${ }^{[43]}$ Gray $^{[44]}$ emphasized that credibility can be explained almost in similar terms as internal validity. In this study, all interviews were audiotaped and field notes were taken as back up. Data was translated ver- batim and interpreted by the researcher. The services of the independent were sought to check correctness of translation and interpretation of data.

\subsubsection{Dependability}

This criterion answered the question regarding the replication of the study and the degree in which it would yield similar findings. During coding, independent analyst served as co-coders to ensure that the coded data was dependable. Where opinions about coding emerged and discussed until consensus was reached.

\subsubsection{Confirmability}

This criterion established that the data represented the information that the participants provided and that the interpretations were not clouded with the researcher's imagination or expectations. During the coding, both promoters will serve as co-coders so as to ensure that the coded data will be a true representation of the participants' data. Creswell ${ }^{[45]}$ stated the use of member checking, e,g. taking parts of the semi-polished product back to the participants as a follow-up interview for them to comment on the findings.

\subsubsection{Transferability}

Transferability the degree to which results of qualitative research can be transferred to other contexts or settings with other participants. ${ }^{[46]}$ The researcher used purposive sampling, whereby the participants had experience in leadership and in-depth knowledge, communication skills and interview techniques, dense description about the context, participants and methodology. A dense, thick description of results was supported by direct quotations of participants.

\section{Results}

The significant findings from the qualitative and quantitative research are synthesized and integrated with prior research and theory reviewed. The point of departure that has been used and on which the synthesis of findings has been done in the manner in which MLQ was designed as well as the emergent themes and sub-themes form the qualitative research. The key themes were: transformation is a challenge, transformation is an inclusive process and transformation is dropping standards. The sub-themes were as follows: transformation is a challenge (lack of qualified lecturers, no standardization of curriculum and national mandate implemented blindly) transformation is an inclusive process (leader support, transformation opened doors and actualization of the vision and mission) dropping of standards (different calibre of students enrolled, changes in the nursing profession and increased intake of students). It emerged from the qualitative research that the present system of education requires that academic nurse leaders and as members of the governance 
structures be adequately skilled in policy interpretation and implementation thereof. The research revealed that transformational leadership is experienced differently by ANLs and vice-principals and subject heads. ANLs experienced transformation as a challenge due to the shortage of skilled lecturers and the department's mandate to increase nurse production and resorted to employing inexperienced lecturers. ANLs reiterated that the head office controls nursing colleges. It stifled the transformation as NEIs' has a limited budget allocated from the equitable share budget. ANLs reported powers were in hands of the head office and felt micromanaged. ANLs experienced that there was a slow move from autocracy to democracy. ANLs felt that it would be valuable to be given complete autonomy and be declared HEIs' or transferred to the Department of Education.

In quantitative research, $\mathrm{t}$-tests for the difference of means between the ANLs and followers were analyzed and the results indicated that ANLs rated themselves slightly higher on their leadership styles whereas followers rated ANLs' leadership styles very low. The results indicated that there was a significant difference between ANLs and lecturers. The results indicated that ANLs in the NEI's' engaged in the transformational leadership given to the MLQ to a low to moderate degree especially to: Interpersonal Relationship, mean: 2.86 and SD: 0.75; Communication, mean:3.23 and SD: 0.61 .

\section{Discussion}

The objective was reached by using theory generative design based on the results of the in-depth one to one interviews and focused group interviews with ANLs. A detailed descriptive of the design was given previously in this research document. The findings of the research suggested that a quest to develop a model through capacity development could be achieved, and recommended that the ANLs to be engaged in this development because a quest for model development is a life long process. The literature reviewed indicated that in order for nursing education leaders to quest for model development through capacity development, they need to be engaged in lifelong learning and developing. The concepts forming the main concepts were analyzed separately, looking at the dictionary meaning and the subject use of the concepts. A list of the main criteria from the dictionary meanings and the subject sources. This was further reduced to essential criteria.
The essential criteria were further synthesized to form the main definition of the main concepts. A visual representation depicting the structure and process of the model was then developed. Deductive reasoning was utilized as a method of inferring relationship statements from the described model. The description of the model development process, followed on a synergetic approach, using steps applicable to theory construction and development. Finally, the methodology resulted in the formulation, description and critical reflection of the model for transformational leadership.

\section{Conclusion}

This article described the research design and method employed to develop a model for transformational leadership for ANLs. A theory development, descriptive, exploratory, contextual, qualitative and quantitative research design in nature. The research objectives were formulated in two phases to enable exploration, identification, and definition of concepts (phase 1) and for model development (phase 2). Data collected by way of individual interviews for college principals and focus group interviews for vice-principals and subject heads and questionnaires for lecturers, students, and administrative staff. The process of model development described, based on a synergetic approach, which capitalizes on the most useful proposed steps by Chinn and Kramer ${ }^{[21]}$ and Walker and Avant. ${ }^{[22]}$ Measures used to ensure the trustworthiness of the study described according to Lincoln and Guba. ${ }^{[42]}$ The hypothesis of the research presented and the research design outlined. Information regarding the sample size and number of participants included in the final statistical analysis presented. An overview of the data collection method was then given. The instrument used in this research, as well as their reliability and validity, discussed in detail. Finally, the statistical analysis of the hypothesis was highlighted.

\section{ACKNOWLEDGEMENTS}

The researcher would like to thank all the Provincial Departments of Health for giving permission for the study to be conducted and for volunteered participants. This research was self-funded.

\section{Conflicts OF InTEREST Disclosure}

The author declares there is no conflict of interest.

\section{REFERENCES}

[1] Berkovich I. School leaders and transformational leadership theory: time to part ways? Journal of Educational Administration. 2016;
54(5): 609-22. https://doi.org/10.1108/JEA-11-2015-010

0

[2] Bush T. Instructional and transformational leadership: Alternative 
and complementary models. Educational Management Administration \& Leadership. 2014; 42(4): 443-4. https://doi.org/10.1 $177 / 1741143214526830$

[3] Hallinger P. Surfacing a hidden literature: A systematic review of research on educational leadership and management in Africa. 2017. https://doi.org/10.1177/1741143217694895

[4] Hallinger P. Leading educational change: Reflections on the practice of instructional and transformational leadership. Cambridge Journal of Education. 2003; 33(3): 329-52. https ://doi.org/10.1080/ 0305764032000122005

[5] Dvir T, Eden D, Avolio BJ, Shamir B. Impact of transformational leadership on follower development and performance: A field experiment. Academy of Management Journal. 2002; 45(4): 735-44. https://doi.org/10.2307/3069307

[6] Bass BM, Avolio BJ. Transformational leadership and organizational culture. Public Administration Quarterly. 1993; 112-21.

[7] Bass BM. Two decades of research and development in transformational leadership. European Journal of Work and Organizational Psychology. 1999; 8(1): 9-32. https://doi.org/10.1080/1359 43299398410

[8] Mittal S, Dhar RL. Transformational leadership and employee creativity: mediating role of creative self-efficacy and moderating role of knowledge sharing. Management Decision. 2015; 53(5): 894-910. https://doi.org/10.1108/MD-07-2014-0464

[9] Eyal O, Roth G. Principals' leadership and teachers' motivation: Selfdetermination theory analysis. Journal of Educational Administration. 2011; 49(3): 256-75. https://doi.org/10.1108/0957823111 1129055

[10] Sun J, Leithwood K. Transformational school leadership effects on student achievement. Leadership and Policy in Schools. 2012; 11(4): 418-51. https://doi.org/10.1080/15700763.2012.681001

[11] Burns JM. Leadership New York. NY: Harper and Row Publishers. 1978.

[12] Yahaya R, Ebrahim F. Leadership styles and organizational commitment: a literature review. Journal of Management Development. 2016; 35(2): 190-216. https ://doi .org/10.1108/JMD-01-201 5-0004

[13] Meleis AI. Theoretical nursing: Development and progress: Lippincott Williams \& Wilkins; 2011.

[14] Dickoff J, James P, Weidenbach E. Practice-oriented research (Part II). Nursing Research. 1968; 17: 545-54. PMid:5187315 https: //doi.org/10.1097/00006199-196811000-00014

[15] Morris D. Middle range theory: Role inEducation 1996.

[16] Chinn P, Kramer M. Knowledge Development in Nursing. 9th ed. Elsevier Mosby; 2015.

[17] Chinn P, Jacobs M. Theory and nursing: A systematic approach 2 nd ed. St Louis, Missouri, CV Mosby. 1987.

[18] Corbin J, Strauss A. Basics of Qualitative Research: Techniques and Procedures for Developing grounded theory. 3rd ed. California: Sage; 2015.

[19] Strauss A, Corbin J. Grounded theory methodology. Handbook of Qualitative Research. 1994; 17: 273-85.

[20] Burns NA, Grove SK, Barcelo TI. Burns \& Grove's Understanding Nursing Research: Building an Evidence-based Practice. 2013.

[21] Chinn P, Kramer M. Knowledge Development in Nursing: Theory and process. 9th ed. Utah: Elsevier; 2014.

[22] Walker L, Avant K. Strategies for Theory Construction in Nursing. Boston: Pearson; 2011.

[23] Morse JM, Mitcham C, Lenz ER. Concept Analysis in Nursing Research: A Critical Appraisal. 1996.

[24] Avant K, Walker L. Strategies for Theory Construction in Nursing. 6th ed. Harlow: Pearson; 2015.
[25] Yilmaz K. Comparison of quantitative and qualitative research traditions: Epistemological, theoretical, and methodological differences. European Journal of Education. 2013; 48(2): 311-25. https://doi.org/10.1111/ejed.12014

[26] LINDA NS, PHETLHU DR, KLOPPER HC. Significance of literature when constructing a theory: A selective.

[27] Kemerling G. Aristotle: Ethics and virtues. Retrieved February. 2001; 20: 2001 .

[28] Polit D, Beck C. Nursing Research: Generating and Assessing Evidence for Nursing Practice. 10th ed. Philadephia: Wolters Kluwer; 2017.

[29] Babbie E. The Practices of Social Research. London: Wadsworth Cangage learning; 2013.

[30] Gray J, Grove S, Sutherland S. Burn's Grove The Practice of Nursing Research. 8th ed. Saunders; 2016.

[31] Denzin N, Lincoln Y. The Sage Handbook of Qualitative Research 4th ed. Los Angelos: Sage; 2011.

[32] Nzimande B. What is Transformation, A Memorial Lecture. In: Education, editor. 2009.

[33] Seidman I. Interviewing as a Qualitative Research: A Guide for Researchers in Education and the Social Sciences. 4th ed. New York City: Teachers College Press; 2013.

[34] Krueger RA, Casey MA. Focus groups: Thousand Oaks, CA: Sage; 2000.

[35] Krueger RA, Casey M. Focus Groups: A Practical Guide for Applied Research. 5th ed. Los Angeles: Sage; 2015.

[36] Parker A, Tritter J. Focus group method and methodology: current practice and recent debate. International Journal of Research \& Method in Education. 2006; 29(1): 23-37. https ://doi .org/10 .1080/01406720500537304

[37] Antonakis J, Avolio BJ, Sivasubramaniam N. Context and leadership: An examination of the nine-factor full-range leadership theory using the Multifactor Leadership Questionnaire. The Leadership Quarterly. 2003; 14(3): 261-95. https://doi.org/10.1016/S1 048-9843(03) 00030-4

[38] Avolio BJ, Bass BM, Jung D. Re-examining the components of transformational and transactional leadership using the Multifactor Leadership. Occupational and Organizational Psychology. 1999; 71(4): 441-62. https://doi.org/10.1348/096317999166789

[39] Cortina JM. What is the coefficient alpha? An examination of theory and applications. Journal of Applied Psychology. 1993; 78(1): 98. https://doi.org/10.1037/0021-9010.78.1.98

[40] Henning E, van Rensburg W, Smit B. Finding Your Way in Qualitative Research. 1st ed. Pretoria: Van Schaik; 2004.

[41] Pope C, Ziebland S, Mays N. Qualitative research in health care: analyzing qualitative data. BMJ: British Medical Journal. 2000; 320(7227): 114. PMid:10625273 https://doi.org/10.1136/bm j.320.7227.114

[42] Lincoln Y, Guba E. Naturalistic Inquiry. 1985.

[43] Polit DF, Beck CT. Nursing Research: Generating and Assessing Evidence for Nursing Practice. 10th ed. Philadephia: Wolters Kluwer; 2017.

[44] Gray J. Qualitative Research Methods. In: Gray J, Grove SK, Sutherland S, editors. Burns and Grove's The Practice of Nursing Research: Appraisal, Synthesis and Generation of Evidence. 8th ed. Missouri: Elsevier; 2017.

[45] Creswell J, Creswell J. Research Design: Qualitative, Quantitative \& Mixed Methods Approaches. 5th ed. Los Angelos: Sage Edge; 2018.

[46] Polit DF, Beck CT. Nursing Research: Generating and Assessing Evidence for Nursing Practice. 9th ed. Philadephia: Wolter Kluwer/Lippincott Williams \& Wilkins; 2012. 